\title{
An Integrated Process and Digitalization Perspective on the Shipping Supply Chain - a Literature Review
}

\author{
Feibert, Diana Cordes; Hansen, Mette Sanne; Jacobsen, Peter
}

Published in:

2017 IEEE International Conference on Industrial Engineering and Engineering Management

Link to article, DOI:

10.1109/IEEM.2017.8290113

Publication date:

2017

Document Version

Publisher's PDF, also known as Version of record

Link back to DTU Orbit

Citation (APA):

Feibert, D. C., Hansen, M. S., \& Jacobsen, P. (2017). An Integrated Process and Digitalization Perspective on the Shipping Supply Chain - a Literature Review. In 2017 IEEE International Conference on Industrial Engineering and Engineering Management IEEE. https://doi.org/10.1109//EEM.2017.8290113

\section{General rights}

Copyright and moral rights for the publications made accessible in the public portal are retained by the authors and/or other copyright owners and it is a condition of accessing publications that users recognise and abide by the legal requirements associated with these rights.

- Users may download and print one copy of any publication from the public portal for the purpose of private study or research.

- You may not further distribute the material or use it for any profit-making activity or commercial gain

- You may freely distribute the URL identifying the publication in the public portal 


\title{
An Integrated Process and Digitalization Perspective on the Shipping Supply Chain - a Literature Review
}

\author{
D. C. Feibert ${ }^{1,2}$, M. S. Hansen ${ }^{1}$, P. Jacobsen ${ }^{1}$ \\ ${ }^{1}$ Department of Management Engineering, Technical University of Denmark, Kgs. Lyngby, Denmark \\ 2 (dife@dtu.dk)
}

\begin{abstract}
The maritime transport industry operates in an environment characterized by fluctuating fuel prices and low freight rates in a dynamic competitive market. Shipping companies must therefore adopt responsive supply chains whilst containing costs. This study investigates what extant literature can offer from an integrated digitalization and business process management perspective to enhance supply chain performance for shipping companies. The main themes identified in literature have been categorized according to their contributions to achieving responsive and efficient supply chains. Furthermore, the drivers of enhanced supply chain performance have been identified and an agenda for future research is proposed. This study therefore contributes to the research field of maritime transport by enfolding extant literature and guiding decision makers in their efforts to achieve responsive and adaptive shipping supply chains.
\end{abstract}

Keywords - Shipping supply chain, digitalization, business process management, efficiency

\section{INTRODUCTION}

The maritime transport industry faces fluctuating fuel prices and low freight rates, putting pressure on profit margins for shipping companies. At the same time, shipping companies operate in a dynamic and highly competitive environment requiring more flexible and resilient organizations [1]. Furthermore, the maritime transport industry is network-centric and requires collaboration across the value chain. Shipping companies must therefore achieve cost reductions whilst adopting responsive supply chains (SCs) to stay competitive [2].

Individuals in the shipping value chain are geographically dispersed [2]. Information and communication technologies (ICTs) together with digitalization can enable collaboration across multiple organizations [2], [3], thereby improving the efficiency of operations [3] and providing a competitive advantage by connecting and integrating actors in the value chain [2]. Thus, ICTs and an improved coordination of the transport process are key drivers in enhancing the quality and efficiency of maritime transport [4]. However, the digital evolution in the shipping industry has not enabled data sharing to facilitate a more efficient coupling between SC actors. Thus, track and trace information is rarely available and information from equipment aboard vessels cannot be easily integrated with other systems [3].

In addition to digitalization as a means for achieving efficient and responsive SCs, business process management (BPM) provides tools for improving process performance and reducing costs [5]. Technologies can enable the reengineering of processes and improve performance [6]-[9], hence technologies and processes can work together to achieve performance improvements.

This paper investigates what extant literature offers in terms of improved efficiency and responsiveness in the shipping SC. Thus, the following research question (RQ) is investigated: How can shipping supply chains become more efficient and responsive from an integrated digitalization and BPM perspective? Efficiency refers to the economic use of resources [10], [11], and responsiveness is "the ability of the manufacturing system or organization to respond to customer requests in the marketplace" [12]. The RQ is answered through a literature review based on 19 papers. The study focuses on processes in the shipping SC rather than the optimization of routes. Fig. 1 illustrates the boundaries of the shipping SC investigated in this study. The paper identifies the main themes in literature considering the improvement of shipping SCs. Moreover, key enablers of efficient and responsive shipping SCs are identified. Finally, an agenda for future research is proposed.

\section{METHODOLOGY}

Papers for the literature review were identified by searching a combination of and variations over the keywords "shipping supply chain", "process management", and "digitalization" using a Boolean search string. The search was limited to the period 1990 to 31 May 2017 and English language scientific papers. The search resulted in 385 hits across three databases: 140 in EBSCO, 150 in Scopus and 95 in Science Direct. Papers were selected which consider the improvement or performance measurement of shipping SC processes. Based on these selection criteria, 19 papers were selected.

The literature review is divided into two parts: a descriptive analysis and a thematic analysis [13]. The descriptive analysis provides an account of the paper details, i.e. publication year, geographical region, applied method and journal. The thematic analysis then elucidates what is known about the research field.

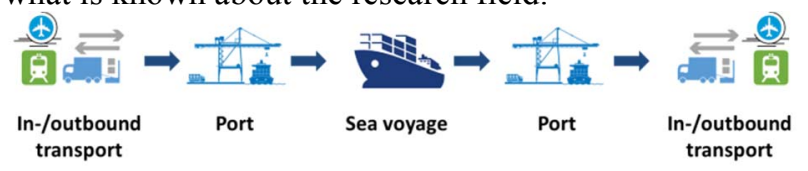

Fig. 1. The shipping supply chain (adapted from [3]) 


\section{RESULTS OF THE LITERATURE REVIEW}

\section{A. Descriptive Analysis}

The distribution of reviewed papers per year is illustrated in Fig. 2, indicating a peak in published papers in 2011, but an otherwise low level of publications. One explanation of the peak could be an increased focus on efficiency in response to the 2008 financial crisis. The studies in the reviewed papers were carried out in Europe $(21 \%)$, Asia $(16 \%)$, multiple regions $(21 \%)$, or was not specified (42\%). The most prevalent method applied is case research $(26 \%)$, followed by conceptual papers (21\%), surveys (16\%), mathematical modelling (16\%), other empirical studies (11\%) and mixed methods (11\%). The papers were published in 14 different journals; $21 \%$ from both the Maritime Policy \& Management journal and Transportation Research. The disparity of journals and publication years together with case research being the prevailing method indicate that research on digitalization and BPM in shipping is an emerging field.

\section{B. Thematic Analysis}

The following thematic analysis is divided into two sections according to the RQ: digitalization and BPM.

Digitalization. The efficiency of operations in the shipping industry is vital for meeting customer requirements [9]. ICTs can be viewed as the backbone of supply chain management (SCM) and can support companies in aligning their business with customer needs [14]. Thus, ICTs can enhance the service provided by shipping companies [2], [9]. In addition, ICTs can provide significant benefits, including increased efficiency and security, improved internal controls, and reduced costs. However, high costs, compatibility issues and process interoperability problems impede technology adoption in the shipping industry [2]. A Greek study shows that ICT applications mainly relate to ship safety and less on commercial transactions. Moreover, the application of technologies to improve operations is limited [2].

In applying IT to drive productivity, different IT capabilities are necessary at each stage of IT adoption, i.e. the decision, implementation, and operating phases. In the decision phase, capabilities are necessary which 1) enable the identification of productivity improving IT investments, 2) align the IT and business strategy, and 3) respond to changes and trends in the external environment. In the implementation phase, necessary capabilities relate to 1) the ability to manage IT projects, 2) ensuring organizational readiness for IT changes, and 3) co-adaptability, which ensures connectivity to external partners and enables information and knowledge sharing. In the operating phase, important capabilities concern 1) the ability to strengthen IT versatility, 2) routinization, regular monitoring and continuous improvement of IT, and 3) the ability to ensure dynamic service enhancements through IT, particularly by furthering the reach to more partners in the SC [9].

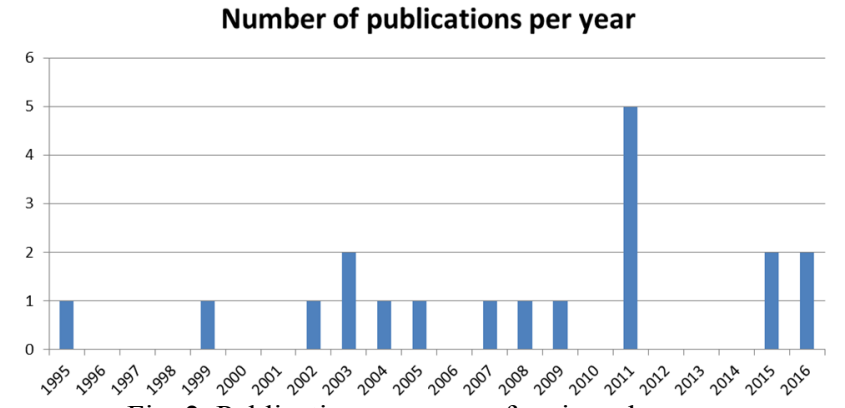

Fig. 2. Publications per year of reviewed papers

It is clear that a firm's capabilities depend on the skills of the employees. Furthermore, the organization must be ready to embrace the changes induced by new IT. The organizational aspect of IT implementation and digitalization is therefore evident.

The shipping industry consists of a large number of autonomous actors working independently [3], [15]. However, these actors must interact closely at certain points in time to fulfill their purpose [3]. Shipping companies should therefore aim to integrate their value chain to achieve seamless operations. Virtual collaboration can improve the speed and reduce the cost of providing a service whilst adding value [2]. Sharing real-time information facilitates seamless services, ensures cost-efficient passage at sea [2], [3], reduces transaction costs and risks [2], and can improve operations across the entire SC [16]. It therefore becomes vital that companies are capable of combining worker knowledge with available information, i.e. analytics, to increase the efficiency of operations [2]. Furthermore, IT evidently holds an important role in integrating SC processes [17]. However, as maritime transports become an integrated part of the door-to-door $\mathrm{SC}$, it is vital that all modes of transport adopt the same ICT infrastructure [16].

In addition to efficiency gains, real-time information sharing enables responsiveness, e.g. through updated voyage plans [3]. Estimated time of arrival and departure therefore becomes vital information to ensure efficient port operations. A coordinated transportation system is required at ports to ensure seamless operations at sea, upon arrival at and departure from ports, and in connection with transport beyond the sea [3].

Advanced IT systems, particularly with a real-time tracking capacity, are considered a major resilience measure. Conversely, one of the major risks identified in the shipping industry also relates to IT systems [1]. Paradoxically, IT therefore both poses a major risk in the $\mathrm{SC}$ and enables SC resilience.

$B P M$. Modelling business processes can enable the analysis of operations in the shipping industry to identify waste and improve processes [18]. Value stream mapping, a lean tool, can facilitate waste elimination and enable just-in-time (JIT) operations in ports [19]. A Greek study shows that assessing as-is and to-be processes reveals potential time savings of up to $50 \%$ in a port by applying ICTs [18]. Technologies can therefore act as enablers of process improvements. 
The application of six sigma tools such as the DMAIC methodology, i.e. Define - Measure - Analyze Improve - Control, can enable lean and green maritime operations and improve performance in terms of vessel speed, exhaust gas temperature and fuel consumption [20]. Furthermore, Saeed Nooramin et al. demonstrate how six sigma can reduce congestion in a container terminal by examining and reducing variations in truck waiting times. Through a cause-effect analysis, the causes of variation can be identified. Moreover, a failure mode and effect analysis (FMEA) offers insights into the most important failure causes. Based on the cause-effect and FMEA analyses, an improvement plan can be devised and proper control methods put in place [21].

To improve customer service, ports may eliminate waste to become lean [22]. Becoming lean could improve the timeliness and reliability of ports. Furthermore, continuous measurement of port performance can support the elimination of waste and the development toward a lean port. To achieve lean ports, a total quality management (TQM) approach is suggested, which provides continuous feedback on port performance. This continuous feedback approach enables responsiveness by continuously adopting corrective measures [22]. As ports link outside flows, serving as an intersection for multimodal transport [23], ports must adopt an extended view of quality management to include business partners [14]. Ports operate as part of a network of ports. To optimize the network, all members of the network must adopt a lean or flexible structure to become responsive [14]. Rather than one lean port in isolation, establishing a network of lean ports reaps the most benefits. To achieve a lean port network, ports must be willing to collaborate and share information [22].

Marlow and Paixão argue that ports need to become agile to better respond to changes in customer demand [19], [22]. Furthermore, the authors argue that establishing lean processes is a prerequisite for creating agile processes [22]. This transition should transpire through a series of developments beginning with the application of business process reengineering (BPR), which is replaced by a TQM approach in the following stages. These subsequent stages progress through a JIT stage, to a lean stage, to an agile stage. Furthermore, the authors argue that this progression facilitates port integration [19].

As a lean tool, Marlow and Paixão argue that JIT can support ports in becoming agile [22]. Collaborative decision making can support JIT operations in ports through collaboration and process integration, e.g. to increase berth productivity [3]. The integration of business processes across organizations in the SC enables SC integration. Lam and Bai emphasize that shipping companies should adopt measures such as creating strategic alliances and SC relationship management to mitigate SC risks [1]. Furthermore, integrating the shipping SC can increase SC profits [15]. Lam and van de Voorde formulate four different strategies for SC integration based on two dimensions: 1) the number of integrated SC members and 2) the number of integrated types of activities. The four strategies are as follows: 1) low integration, 2) partner-focused integration, 3) activity-focused integration, and 4) high integration. Although the shipping industry has moved toward higher levels of integration in recent years, most shipping companies have adopted a low integration strategy [15].

Bichou and Gray propose an integrated port system between the port and SC partners [23]. The authors suggest that to achieve competitive advantages, port operators should seek to integrate the SC by considering the following aspects: 1) use of ICTs, 2) information sharing, 3) relationships with shipping lines, 4) valueadded service, 5) integration of transport modes, 6) channel integration and practice, and 7) relationships with inland transport operators [24].

Shipping companies in general only exhibit average market efficiency. To enable benchmarking of relative efficiency, consistent measures need to be developed. Stochastic frontier analysis (SFA) and data envelopment analysis (DEA) can establish the efficient frontier corresponding to the optimal relationship between financial inputs and outputs. A benchmarking study of the dry bulk, wet bulk and container markets shows that tanker companies are relatively more market efficient than other shipping companies, whereas container firms are relatively more operating efficient than for the other two sectors [25]. Similarly, SFA and DEA have been applied to calculate port efficiency [26], [27].

Closely related to benchmarking is the concept of performance measurement. Performance consists of an efficiency and effectiveness aspect, where effectiveness relates to the right output at the right time at the right cost, and efficiency relates to making things faster, cheaper and with less waste. Marlow et al. identify three types of processes: 1) interface processes, i.e. ports and inland terminals, 2) transport processes, i.e. waterborne, road and rail operators, and 3) infrastructure processes, i.e. road and rail infrastructures. The authors propose effectiveness measures for each process type to ensure effective processes before efficient processes [22]. From a port point of view, measuring simple throughput is not sufficient to assess terminal efficiency [24]. Efficiency could be measured in terms of container mix, delays, crane hours, and vessel size and cargo exchange [28]. However, Bichou and Gray argue that ports need to move away from such a profit/output perspective. They propose a framework for port performance measurement which integrates a logistics and SC perspective. From a logistics perspective, ports should move toward a process improvement focus. Similarly, from a SCM perspective, ports should aim to measure performance based on benchmarking and through collaboration with $\mathrm{SC}$ partners. However, measuring SC performance poses some methodological challenges and requires partnership collaboration and information sharing in the SC [23].

Table I lists the themes identified in literature and indicates how each theme relates to efficiency/responsiveness and digitalization/BPM. 
TABLE I

Themes identified in literature (no. of papers)

\begin{tabular}{|c|c|c|}
\hline & Digitalization & BPM \\
\hline 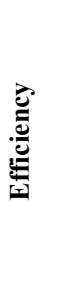 & $\begin{array}{l}\text { - ICTs (6) } \\
\text { - ICT infrastructure (1) } \\
\text { - Information sharing (5) } \\
\text { - IT capabilities (1) } \\
\text { - Analytics (1) }\end{array}$ & $\begin{array}{l}\text { - Process modelling (2) } \\
\text { - } \text { TQM (3) } \\
\text { - Lean/JIT (2) } \\
\text { - Six sigma (2) } \\
\text { - } \text { BPR (1) } \\
\text { - Benchmarking (3) } \\
\text { - Perf. measurement (4) } \\
\text { - SC integration (10) }\end{array}$ \\
\hline 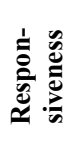 & $\begin{array}{l}\text { - ICTs (1) } \\
\text { - Real-time data (4) } \\
\text { - Information sharing (6) } \\
\text { - Analytics (1) }\end{array}$ & $\begin{array}{l}\text { - } \text { Lean/JIT (2) } \\
\text { - Agility (2) } \\
\text { - SC integration (10) }\end{array}$ \\
\hline
\end{tabular}

Furthermore, Fig. 3 depicts the conceptual framework developed in this paper and illustrates the digitalization and BPM constructs identified in literature which enable improved SC performance in addition to the relations identified between the constructs. SC performance in this case consists of a responsiveness and efficiency aspect. The constructs in Fig. 2 are enabled by either digitalization or process management. Furthermore, digitalization and process management together with SC integration can improve SC performance in terms of responsiveness and efficiency.

In relation to the shipping $\mathrm{SC}, 49 \%$ of the reviewed papers relate to port operations and only $21 \%$ consider the broader SC. Furthermore, studies related to digitalization tend to have a broader SC perspective.

\section{DISCUSSION}

Digitalization and BPM have proven to support each other; ICTs can increase process efficiency, and processes need to be aligned to ICTs. ICTs are an inherent part of BPR and process innovation and can facilitate radical process improvements [7], [29]. The findings of this study support the perception that ICTs and processes do not function in isolation and that an integrated approach to BPM and digitalization is necessary.

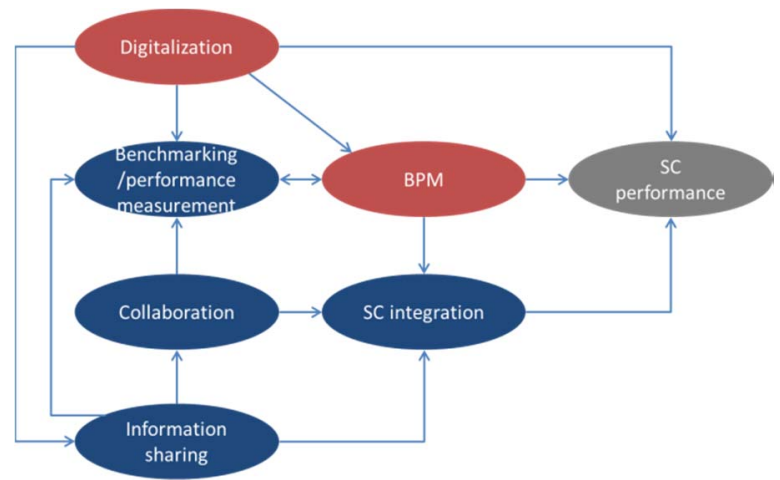

Fig. 3. Key digitalization and BPM constructs enabling improved SC performance in shipping
The literature review shows that digitalization can enable benchmarking, performance measurement and information sharing. Information sharing can in turn facilitate collaboration and benchmarking/performance measurement as illustrated in Fig. 3. Many of the reviewed papers, e.g. [15], [24], mention SC integration as a means to improve SC performance. Digitalization, $\mathrm{BPM}$, collaboration and information sharing contribute to SC integration. According to Cooper et al., SCM can be defined as "the integration of business processes from end user through original suppliers that provides products, services and information that add value for customers" [30]. This definition of SCM together with the identified importance of SC integration in literature suggests that a SCM perspective is both applicable and important for the improvement of shipping SCs. However, there seems to be a more narrow logistics focus in the shipping SC, e.g. as indicated in [23] by the focus of ports on logistics measures and the methodological challenges in calculating SC performance. Moreover, the literature review reveals that studies tend to focus on specific tiers in the SC rather than the entire SC.

In terms of practical implications, how the identified themes contribute to efficiency and responsiveness can direct shipping managers toward those management approaches which increase either efficiency, responsiveness or both. Similarly, acknowledging the enablers or drivers of SC performance from a digitalization and BPM perspective can help decision makers focus the attention of new management initiatives.

This study has enfolded extant literature regarding the improvement of shipping SCs from a BPM and digitalization perspective and shed light on future research opportunities. The study reveals that extant literature in the field is limited. The selected 19 papers are deemed representative of the field and for providing initial conclusions on the role of digitalization and BPM to enhance shipping SC performance. The main limitation of the study is the exclusion of operational research papers, which could be explored more in future research. The investigated process-oriented literature seems to focus on operations within each SC tier. Moreover, most of this literature is concerned with port operations. Conversely, the digitally oriented literature seems to have a wider SC perspective. One avenue for future research could be to investigate processes outside of ports, e.g. on vessels, administration, and collaboration between vessels and company headquarters. Furthermore, a broader SCM perspective is needed to facilitate a shift from the current single tier focus dominating BPM literature to an SCM approach, which digitalization literature has embraced to a larger extent. Another research opportunity lies in the applicability of different types of BPM and SCM approaches which have not been investigated for the shipping SC, e.g. process standardization, SC design and $\mathrm{SC}$ innovation. Furthermore, the identified themes within digitalization and BPM have only been investigated to a limited extent and calls for further research. 


\section{CONCLUSION}

A literature review concerning the shipping SC from a process and digitalization perspective was conducted. The study identified and categorized the major themes in literature according to digitalization/BPM and efficiency/responsiveness. Furthermore, the main BPM and digitalization enablers or drivers of shipping SC performance have been identified. Finally, a research agenda for future research was proposed.

\section{ACKNOWLEDGMENT}

The authors would like to thank Orients Fond for funding this research.

\section{REFERENCES}

[1] J. S. L. Lam and X. Bai, "A quality function deployment approach to improve maritime supply chain resilience," Transp. Res. Part E Logist. Transp. Rev., vol. 92, pp. 1627, 2016.

[2] N. Nikitakos and M. A. Lambrou, "Digital Shipping: The Greek Experience," Res. Transp. Econ., vol. 21, pp. 383417, 2007.

[3] M. Lind, A. Brödje, S. Haraldson, M. Hägg, and R. Watson, "Digitalisation for sustainable sea transports," in Clean mobility and intelligent transport systems, J.-C. Lin and F. Michele, Eds. IET, 2015, pp. 187-217.

[4] Z. Pietrzykowski, "Maritime Intelligent Transport Systems," in International Conference on Transport Systems Telematics, 2011, pp. 455-462.

[5] M. Zairi, "Business process management: a boundaryless approach to modern competitiveness," Bus. Process Manag. J., vol. 3, no. 1, pp. 64-80, 1997.

[6] J. Karimi, T. M. Somers, and A. Bhattacherjee, "The Impact of ERP Implementation on Business Process Outcomes: A Factor-Based Study," J. Manag. Inf. Syst., vol. 24, no. 1, pp. 101-134, 2007.

[7] T. H. Davenport, Process Innovation: Reengineering Work through Information Technology. Boston, Massachusetts: Harvard Business School Press, 1993.

[8] M. Hammer, "Reengineering Work: Don't Automate, Obliterate," Harv. Bus. Rev., vol. 68, no. 4, pp. 104-112, 1990.

[9] G. Pan, S.-L. Pan, and C.-Y. Lim, "Examining how firms leverage IT to achieve firm productivity: RBV and dynamic capabilities perspectives," Inf. Manag., vol. 52, no. 4, pp. 401-412, 2013.

[10] J. T. Mentzer and B. P. Konrad, "An efficiency/effectiveness approach to logistics performance analysis," J. Bus. Logist., vol. 12, no. 1, pp. 33-61, 1991.

[11] G. Chow, T. D. Heaver, and L. E. Henriksson, "Logistics Performance : Definition and Measurement," Int. J. Phys. Distrib. Logist. Manag., vol. 24, no. 1, pp. 17-28, 1994.

[12] M. Holweg, "The three dimensions of responsiveness," Int. J. Oper. Prod. Manag., vol. 25, no. 7, pp. 603-622, 2005.

[13] D. Tranfield, D. Denyer, and P. Smart, "Towards a Methodology for Developing Evidence-Informed Management Knowledge by Means of Systematic
Review,” Br. J. Manag., vol. 14, no. 3, pp. 207-222, 2003.

[14] H. Tran, S. Cahoon, and S.-L. Chen, "A Quality Management Framework for Seaports in their Supply Chains in the 21st Century," Asian J. Shipp. Logist., vol. 27, no. 3, pp. 363-386, 2011.

[15] J. S. L. Lam and E. van de Voorde, "Scenario analysis for supply chain integration in container shipping," Marit. Policy Manag., vol. 38, no. 7, pp. 705-725, 2011.

[16] A. Morrall, J. Rainbird, T. Katsoulakas, I. Koliousis, and T. Varelas, "e-Maritime for automating legacy shipping practices," Transp. Res. Procedia, vol. 14, pp. 143-152, 2016.

[17] P. Evangelista and A. Morvillo, "Alliances in Liner Shipping: an Instrument to Gain Operational Efficiency or Supply Chain Integration?," Int. J. Logist. Res. Appl., vol. 2, no. 1, pp. 21-38, 1999.

[18] D. V. . Lyridis, T. . Fyrvik, G. N. . Kapetanis, N. . Ventikos, P. . Anaxagorou, E. . Uthaug, and H. N. Psaraftis, "Optimizing shipping company operations using business process modelling," Marit. Policy Manag., vol. 32, no. 4, pp. 403-420, 2005.

[19] A. C. Paixão and P. Bernard Marlow, "Fourth generation ports - a question of agility?," Int. J. Phys. Distrib. Logist. Manag., vol. 33, no. 4, pp. 355-376, 2003.

[20] G. J. Besseris, "Applying the DOE toolkit on a Lean-andGreen Six Sigma Maritime-Operation Improvement Project," Int. J. Lean Six Sigma, vol. 2, no. 3, pp. 270-284, 2011.

[21] A. Saeed Nooramin, V. Reza Ahouei, and J. Sayareh, "A Six Sigma framework for marine container terminals," Int. J. Lean Six Sigma, vol. 2, no. 3, pp. 241-253, 2011.

[22] P. B. Marlow and A. C. Paixão Casaca, "Measuring lean ports performance," Int. J. Transp. Manag., vol. 1, no. 4, pp. 189-202, 2003.

[23] K. Bichou and R. Gray, "A logistics and supply chain management approach to port performance measurement," Marit. Policy Manag., vol. 31, no. 1, pp. 47-67, 2004.

[24] D.-W. Song and P. M. Panayides, "Global supply chain and port/terminal: integration and competitiveness," Marit. Policy Manag., vol. 35, no. 1, pp. 73-87, 2008.

[25] P. M. Panayides, N. Lambertides, and C. S. Savva, "The relative efficiency of shipping companies," Transp. Res. Part E Logist. Transp. Rev., vol. 47, no. 5, pp. 681-694, 2011.

[26] P. M. Panayides, C. N. Maxoulis, T. Wang, and K. Y. A. $\mathrm{Ng}$, "A Critical Analysis of DEA Applications to Seaport Economic Efficiency Measurement," Transp. Rev., vol. 29, no. 2, pp. 183-206, 2009.

[27] K. Cullinane, D. W. Song, and R. Gray, "A stochastic frontier model of the efficiency of major container terminals in Asia: Assessing the influence of administrative and ownership structures," Transp. Res. Part A Policy Pract., vol. 36, no. 8, pp. 743-762, 2002.

[28] J. L. Tongzon, "Determinants of port performance and efficiency," Transp. Res. Part A, vol. 29, no. 3, pp. 245252, 1995.

[29] M. Hammer and J. Champy, Reengineering the Corporation: A manifesto for business revolution, 1 st ed. New York: HarperCollins Publishers, 1993.

[30] M. C. Cooper, D. M. Lambert, and J. D. Pagh, "Supply chain management: more than a new name for logistics," Int. J. Logist. Manag., vol. 8, no. 1, p. 14, 1997. 